\title{
Improving the Performance of Organic Lead-tin Laminated Perovskite Solar Cells From the Perspective of Device Simulation
}

liangsheng HaO

Shanghai University of Electric Power https://orcid.org/0000-0002-3760-5965

\section{Xuefei Wu}

Shanghai University of Electric Power

Huaning Wang

Shanghai Jiao Tong University

Yubao Song

Xi'an Thermal Power Research Institute co Ltd

\section{Xinxia Ma}

Shanghai University of Electric Power

\section{Zhuoxiong Zeng}

Shanghai University of Electric Power

Jiang Wu ( $\nabla$ sylhlsoqel@163.com )

Shanghai University of Electric Power

\section{Yuting Tao}

Shanghai University of Electric Power

\section{Zhongyu Wang}

Shanghai University of Electric Power

Yihao Liu

Shanghai University of Electric Power

\section{Research Article}

Keywords: Lead-tin laminated structure, SCAPS-1D, Interface defect density, Simulation optimization

Posted Date: October 5th, 2021

DOl: https://doi.org/10.21203/rs.3.rs-872884/v1

License: (c) (i) This work is licensed under a Creative Commons Attribution 4.0 International License. Read Full License 


\section{Abstract}

The toxic lead in traditional perovskite solar cells (PSCs) poses a fatal threat to the environment, and it takes time and technology to complete the transition to lead-free perovskite solar cells. In this work, we introduce a lead-tin laminated perovskite solar cell, which can obviously reduce the toxicity of lead. Our ultimate goal is to study the factors that affect the performance of the device. On the basis of reducing the lead-based perovskite layer, use SACPS-1D (solar cell capacitor simulator) to optimize the parameters to maximize the performance of the entire device. Adjusting the physical parameters, we got the power conversion efficiency (PCE) of $17.59 \%$ and $6.14 \%$ for single-cell lead-based and single-cell tin-based perovskite solar cells respectively, which are close to the experimental results. The simulation results show that under the laminated structure, the thickness of the two perovskite absorber materials based on lead and tin has a certain influence on the performance of the device. After optimization, it is determined that the best thicknesses of lead-based absorption layer (LBA) and tin-based absorption layer (TBA) are $20 \mathrm{~nm}$ and $150 \mathrm{~nm}$ respectively. Optimize the doping concentration of acceptor and donor of the laminated perovskite absorber layer to obtain higher PCE and open circuit voltage $\left(V_{O C}\right)$. The best values are $10^{15} \mathrm{~cm}^{-}$ ${ }^{3}$ and $10^{16} \mathrm{~cm}^{-3}$ for LBA and TBA respectively. We also found that when adjusting the positions of LBA and TBA, the recombination rate under different defect densities verified that the laminated absorption layer close to the light source side dominates the device performance. Provide reference for future optimization of laminated perovskite solar cells. Considering these factors comprehensively, we optimized the device performance parameters as follows: $V_{O C}=0.9266 \mathrm{~V}, J_{S C}=19.5556 \mathrm{~mA} / \mathrm{cm}^{2}, \mathrm{FF}=71.12$ $\%$ and $\mathrm{PCE}=12.89 \%$.

\section{Highlights}

- This work introduces a lead-tin laminated perovskite solar cell, which can obviously reduce the toxicity of lead.

- The effect of the thickness, doping concentration and defect density $\mathrm{N}_{t}$ of the laminated perovskite layer on the device performance and the optimal value of each parameter are explored.

- The intrinsic factors affecting the performance parameters of each device are analyzed in terms of the recombination rate $(R)$, External Quantum Efficiency $(Q E)$ and the hole Fermi energy level $\left(F p_{n}\right)$.

- In a laminated perovskite solar cell, the defect density of the laminated perovskite absorber near the light source side dominates the damage to the overall performance of the device.

- The device performance is improved after optimization: $\mathrm{V}_{\mathrm{OC}}=0.9266 \mathrm{~V}, \mathrm{~J}_{\mathrm{SC}}=19.5556 \mathrm{~mA} / \mathrm{cm}^{2}$, $\mathrm{FF}=71.12 \%$ and $\mathrm{PCE}=12.89 \%$.

\section{Introduction}

Organic/inorganic hybrid perovskite materials have the advantages of large absorption coefficient, high carrier mobility, long exciton diffusion length and low-temperature preparation process (Marchioro et 
al. 2014; Stranks et al. 2013; Xing et al. 2013; Zhou et al. 2014; Jeon et al. 2015; Yang et al. 2015; Arora et al. 2017), which are used in light-emitting diodes (Tan et al. 2014; Wang et al. 2016), solar cells (Kojima et al. 2009; Hou et al. 2015), photodetectors (Ahmadi et al. 2017; Dong et al. 2017), lasers (Xing et al. 2014) and other aspects, so that they have gained wide attention. These excellent intrinsic properties make them more suitable as light-absorbing materials for solar cells, and recently achieved a power conversion efficiency (PCE) of 22\% (Yang et al. 2017). The rate of perovskite/monocrystalline silicon laminated solar cells has increased to $28.0 \%$, showing strong application potential. Although perovskite solar cells have the advantages of high efficiency, abundant raw materials, easy preparation, and low cost, they still have issues to be solved, such as instability, difficulty in packaging, and biological toxicity. Therefore, for the transformation of perovskite solar cells from laboratory to industrialization, a lot of research and effort are needed.

In the early stage of research on lead-based halogen perovskite materials, people began to consider replacing tin with lead congener element for the purpose of low toxicity and environmental protection. However, researchers soon discovered that due to the easy oxidation of divalent tin ions, the tin-based perovskite light-absorbing layer has problems such as high defect density and low carrier lifetime, which makes its development slower than that of lead-based batteries. From the first reported efficiency of $0.9 \%$ in 2012 (Chen et al. 2012), to the beginning of 2019, the efficiency of tin-based batteries has not exceeded the efficiency of $10 \%$. However, from the end of 2019 to 2020, several international research groups (Jiang et al. 2020; Meng et al. 2020; Liu et al. 2020; Meng et al. 2020; Nishimura et al. 2020;) have reported tinbased perovskite solar cells with efficiency over 10\% through different stability optimization methods, providing a good reference for $\mathrm{Sn}-\mathrm{Pb}$ mixed perovskite solar cells. Although the current highest photoelectric conversion efficiency of perovskite solar cells has reached $25.2 \%$, there is still room for improvement in the efficiency of halogen perovskite solar cells, especially the ideal bandgap perovskite solar cells and perovskite laminated cells. On the one hand, the current wide band gap halogen perovskite has been successfully applied to Perovskite/Si tandem cells and Perovskite/CIGS tandem cells, and has achieved a photoelectric conversion efficiency close to $30 \%$. On the other hand, the development of ideal band gap, narrow band gap halogen perovskite solar cells, that is, tin-lead mixed halogen perovskite is also underway. This makes it possible for more efficient single-cell halogen perovskite solar cells and efficient full perovskite tandem cells.

The organization of halogen perovskite and tin-lead mixing are important directions for the development of halogen perovskite solar cells in recent years. Halogen organic perovskites can solve the problem of instability of the perovskite phase caused by inorganic cations (mainly $\mathrm{Cs}^{+}$). In addition to obviously reduce the toxicity of lead, tin-lead mixed halogen perovskite can optimize the halogen perovskite band gap, so as to make the halogen perovskite absorbance layer with ideal band gap and narrow band gap possible. Zhou and Padture group (Chen et al. 2019) applied Sn and Ge mixed inorganic halide perovskite to solar cells for the first time. They used $\mathrm{CsSn}_{0.5} \mathrm{Ge}_{0.5} \mathrm{l}_{3}$ perovskite to achieve an efficiency of $7.11 \%$. Hu et al. carried out research on inorganic $\mathrm{Sn}-\mathrm{Pb}$ mixed halogen perovskite, through the passivation of grain boundaries and surface defects, to achieve a $13.7 \%$ conversion efficiency of $\mathrm{CsSn}_{0.4} \mathrm{~Pb}_{0.6} \mathrm{I}_{3}$ perovskite 
solar cells (Hu et al. 2020). Saliba et al. used Cs/MA/FA mixed cations to obtain perovskite solar cells with good stability and repeatability, with an efficiency of more than $21 \%$ (Saliba et al. 2016).

This work studies a new type of lead-tin laminated halogen perovskite materials, compared with the increasingly mature organic-inorganic hybrid lead-based perovskite materials. On the one hand, halogenbased organic perovskites can solve the problem of instability of the perovskite phase caused by inorganic cations, and the introduction of tin can optimize the band gap of halogen-based perovskites. This is in line with the development trend of assembling more stable and more efficient halogen perovskite solar cell devices. On the other hand, the optimization of lead-tin laminated halogen perovskite solar cells in this work seeks the best ratio of various parameters on the basis of reducing the lead-based perovskite layer, and uses SACPS-1D to optimize the parameters to maximize the overall device Performance.

\section{Materials And Methods}

\subsection{Device structure and parameters}

The simulated lead-tin laminated perovskite structure is shown in Fig 1(a). The device structure is composed of $\mathrm{FTO} / \mathrm{TiO}_{2} / \mathrm{MAPbl}_{3} \mathrm{MASn}_{3} /$ spiro-MeOTAD/Au. Fig 1 (b) shows the energy band diagram of the device structure. The LUMO level of $\mathrm{TiO}_{2}$ matches the minimum conduction band of the lead-tin multilayer perovskite absorber layer, and effective electron transfer occurs between the absorber layer and the gold electrode. The HOMO level of $\mathrm{TiO}_{2}$ is also lower than the maximum value of the valence band of the perovskite, and the absorption layer is effectively blocked without hole migration. The energy bands of the laminated absorbers also satisfy the conditions of both electron and hole transitions. Considering the bad recombination process between device interfaces, we added IDL1 and IDL2 interface defect layers (IDL) between $\mathrm{TiO}_{2} / \mathrm{MAPbl}_{3}$ and $\mathrm{MASnl}_{3}$ / spiro-MeOTAD, respectively, to simulate a perovskite area with a large number of defects (Liu et al. 2014). The selection of device parameters is very important. According to the reported theoretical and experimental research results, we carefully selected relatively reasonable parameters (Liu et al. 2013; Hao et al. 2015; Devi and Mehra 2019; Minemoto and Murata 2014; Löper et al. 2015; Stamate 2003; Poplavskyy and Nelson 2003; Liu and Kelly 2013). Table 1 summarizes the basic physical and device parameter settings of each layer of the simulation. The left and right contact work functions are $4.4 \mathrm{eV}(\mathrm{FTO})$ and $5.1 \mathrm{eV}(\mathrm{Au})$ respectively. All simulations were performed under AM 1.5 lighting.

Table 1. The original parameters of the different layers of the device 


\begin{tabular}{|c|c|c|c|c|c|c|c|}
\hline Parameter & FTO & $\mathrm{TiO}_{2}$ & IDL1 & $\mathrm{MASnI}_{3}$ & $\mathrm{MAPbl}_{3}$ & IDL2 & $\begin{array}{l}\text { Spiro- } \\
\text { MeOTAD }\end{array}$ \\
\hline $\begin{array}{l}\text { Thickness } \\
(\mathrm{nm})\end{array}$ & 500 & 30 & 8.0 & 150 & 150 & 8.0 & 200 \\
\hline $\begin{array}{l}\text { Band gap, } E g \\
(\mathrm{eV})\end{array}$ & 3.5 & 3.2 & 1.41 & 1.41 & 1.55 & 1.55 & 3.17 \\
\hline $\begin{array}{l}\text { Electron } \\
\text { affinity, } \chi(\mathrm{eV})\end{array}$ & 4.0 & 4.26 & 4.17 & 4.17 & 3.90 & 3.90 & 2.05 \\
\hline $\begin{array}{l}\text { Dielectric } \\
\text { Permittivity, } \varepsilon r\end{array}$ & 9 & 9.0 & 8.2 & 8.2 & 6.50 & 6.50 & 3.0 \\
\hline $\begin{array}{l}\text { CB effective } \\
\text { density of } \\
\text { states, Nc } \\
\left(\mathrm{cm}^{-3}\right)\end{array}$ & $2.20 \times 10^{18}$ & $2.0 \times 10^{18}$ & $1.0 \times 10^{18}$ & $1.0 \times 10^{18}$ & $2.2 \times 10^{18}$ & $2.2 \times 10^{18}$ & $2.2 \times 10^{18}$ \\
\hline $\begin{array}{l}\text { VB effective } \\
\text { density of } \\
\text { states, Nv } \\
\left(\mathrm{cm}^{-3}\right)\end{array}$ & $1.80 \times 10^{19}$ & $1.8 \times 10^{19}$ & $1.0 \times 10^{18}$ & $1.0 \times 10^{18}$ & $1.8 \times 10^{18}$ & $1.8 \times 10^{18}$ & $1.8 \times 10^{19}$ \\
\hline $\begin{array}{l}\text { Electron } \\
\text { mobility, } \mu n \\
\left(\mathrm{~cm}^{2} / \mathrm{Vs}\right)\end{array}$ & 20 & 20 & 1.6 & 1.6 & 2.0 & 2.0 & 0.0002 \\
\hline $\begin{array}{l}\text { Hole mobility, } \\
\mu_{p}\left(\mathrm{~cm}^{2} / \mathrm{Vs}\right)\end{array}$ & 10 & 10 & 1.6 & 1.6 & 2.0 & 2.0 & 0.0002 \\
\hline $\begin{array}{l}\text { Shallow } \\
\text { donor density, } \\
N_{D}\left(\mathrm{~cm}^{-3}\right)\end{array}$ & $2.00 \times 10^{19}$ & $1.0 \times 10^{16}$ & 0 & 0 & $1.0 \times 10^{13}$ & $1.0 \times 10^{13}$ & 0 \\
\hline $\begin{array}{l}\text { Shallow } \\
\text { Acceptor } \\
\text { density, } \\
N_{A}\left(\mathrm{~cm}^{-3}\right)\end{array}$ & 0 & 0 & $1.0 \times 10^{12}$ & $1.0 \times 10^{12}$ & 0 & 0 & $2.0 \times 10^{18}$ \\
\hline $\begin{array}{l}\text { Defect } \\
\text { density, Nt } \\
\left(\mathrm{cm}^{-3}\right)\end{array}$ & $1.00 \times 10^{15}$ & $1.0 \times 10^{15}$ & $1.0 \times 10^{18}$ & $1.0 \times 10^{17}$ & $2.5 \times 10^{13}$ & $1.0 \times 10^{17}$ & $1.0 \times 10^{15}$ \\
\hline $\begin{array}{l}\text { Electron } \\
\text { Thermal } \\
\text { Velocity } \mathrm{cm} / \mathrm{s}\end{array}$ & $10^{7}$ & $10^{7}$ & $10^{7}$ & $10^{7}$ & $10^{7}$ & $10^{7}$ & $10^{7}$ \\
\hline $\begin{array}{l}\text { Hole Thermal } \\
\text { Velocity } \mathrm{cm} / \mathrm{s}\end{array}$ & $10^{7}$ & $10^{7}$ & $10^{7}$ & $10^{7}$ & $10^{7}$ & $10^{7}$ & $10^{7}$ \\
\hline
\end{tabular}


We used SCAPS-1D to numerically simulate the device structure. According to the initial parameter values given in Table 1, we simulated two single-cell perovskite solar cells, $\mathrm{FTO} / \mathrm{TiO}_{2} / \mathrm{MAPbl}_{3} /$ spiro$\mathrm{MeOTAD} / \mathrm{Au}$ and $\mathrm{FTO} / \mathrm{TiO}_{2} / \mathrm{MASn}_{3}$ / spiro-MeOTAD/Au. As shown in Table 2, the performance parameters of the single-cell lead-based and single-cell tin-based PSCs obtained are similar to those of the experiment, which verifies the effectiveness of the modeling. After that, we began to simulate lead-tin laminated perovskite solar cells. Fig 2(a) defines the panel for SCAPS-1D, showing the light direction and each layer of the device structure. Fig 2(b) is the energy band diagram, different from single-cell perovskite solar cells, the perovskite absorber layer of the laminated structure generates two built-in electric fields. And HTL and ETL respectively formed a large built-in electric field of $3 \mathrm{~V} / \mu \mathrm{m}$ under high doping concentration, which is in line with the perovskite solar cell with n-i-p structure, being consistent with the existing reports (Ke et al. 2015). Fig 2(c) is the current density-voltage (J-V) obtained by simulation. According to the initial parameters, we get: $\mathrm{V}_{\mathrm{OC}}=1.2578 \mathrm{~V}, \mathrm{~J}_{\mathrm{SC}}=20.5054 \mathrm{~mA} / \mathrm{cm} 2, \mathrm{FF}=30.09 \%$ and $\mathrm{PCE}=8.53 \%$. Laminated cells are a way to break the Shockley-Queisser limit by using two lightabsorbing layers, where the narrow band gap mainly absorbs long-wavelength sunlight, and the wide band gap mainly absorbs short-wavelength sunlight. In Fig. 2(d), under the same initial parameters, we obtained the quantum efficiency curves (QE) of lead-based, tin-based and lead-tin laminated perovskite solar cells respectively. The lead-tin laminated solar cells made up for the wavelengths of sunlight that lead-based could not absorb. The range of the external quantum efficiency curve covers the entire visible spectrum, and the absorption value from $350 \mathrm{~nm}$ to $770 \mathrm{~nm}$ is the strongest, exceeding $50 \%$.

Table 2 Comparison of single-cell lead-based PSCs and single-cell tin-based PSCs with experiments

\begin{tabular}{|lllll|}
\hline $\mathrm{V}_{\mathrm{OC}}(\mathrm{V})$ & $\mathrm{J}_{\mathrm{SC}}\left(\mathrm{mA} / \mathrm{cm}^{2}\right)$ & $\mathrm{FF}(\%)$ & PCE $(\%)$ & Reference \\
\hline 1.142 & 21.75 & 65.0 & 17.59 & This work (lead-based) \\
\hline 1.017 & 22.92 & 75.0 & 17.40 & (Xu et al. 2016) \\
0.9091 & 21.46 & 31.4 & 6.14 & This work (tin-based) \\
\hline 0.880 & 16.80 & 42.0 & 6.40 & (Noel et al. 2014) \\
\hline
\end{tabular}

\section{Results And Discussion}

\subsection{Effect of thickness of laminated perovskite absorption layer on device performance}

For perovskite solar cells, the thickness of the perovskite absorber layer is one of the important factors affecting device performance (Liu et al. 2014). The thickness of the absorption layer is too thin, which is not conducive to effective absorption of photons, resulting in a decrease in battery efficiency. Since the carriers must reach the carrier collection layer from the absorption layer before recombination, too thick absorption layer causes the collection of photogenerated carriers to be hindered. Therefore, reasonable absorption layer thickness can enhance the spectral response of the device, thereby improving the performance of the entire device. It is very meaningful to study the thickness of the absorption layer. 
Taking into account the double-layer absorber layer of the lead-tin laminated perovskite solar cell, we kept the thickness of the LBA (TBA) absorber layer unchanged, changed the thickness of the TBA (LBA), and simulated the performance parameters of each device $\left(\mathrm{V}_{\mathrm{OC}}, \mathrm{J}_{\mathrm{SC}}, \mathrm{FF}, \mathrm{PCE}\right)$. The thickness of each absorption layer is between $20 \mathrm{~nm}$ and $500 \mathrm{~nm}$, and we have obtained $\mathrm{V}_{\mathrm{OC}}, \mathrm{J}_{\mathrm{SC}}$, FF and PCE diagrams under different absorption layer thicknesses, as shown in Fig 3. In Fig 3(a), we analyzed that the thickness of the LBA has a greater impact on the open circuit voltage $V_{O C}$ than the TBA. As the thickness of TBA increases, $V_{O C}$ shows a downward trend. When the thickness reaches $350 \mathrm{~nm}$, the value of $V_{O C}$ is less than 1. The thickness of TBA is less than $150 \mathrm{~nm}$, and with the increase of LBA thickness, the value of $V_{O C}$ is relatively ideal. When the thickness of TBA is controlled at $50 \mathrm{~nm}$, the thickness of LBA has a small peak in $V_{O C}$ in the range of $20 \mathrm{~nm} \sim 200 \mathrm{~nm}$. Fig. 3(b) shows the $\mathrm{J}_{S C}$ curves of different absorption layer thicknesses. In the interval between low LBA thickness and high TBA thickness, or between high LBA thickness and low TBA thickness, $\mathrm{J}_{\mathrm{SC}}$ achieves relatively high values. PCE is an important indicator to measure the performance of the device. From the analysis of the PCE diagram in Fig 3(d), when the thickness of the TBA is greater than 150nm, the PCE of the device decreases rapidly. And when the thickness of TBA is less than 150nm, PCE tends to increase with the thickness of LBA. Considering that the LBA should be reduced as much as possible, we choose the thickness of LBA and TBA to be divided into $20 \mathrm{~nm}$ and $150 \mathrm{~nm}$ as the optimized value.

\subsection{Effect of thickness of laminated perovskite absorption layer on device performance}

For perovskite solar cells, the thickness of the perovskite absorber layer is one of the important factors affecting device performance (Liu et al. 2014). The thickness of the absorption layer is too thin, which is not conducive to effective absorption of photons, resulting in a decrease in battery efficiency. Since the carriers must reach the carrier collection layer from the absorption layer before recombination, too thick absorption layer causes the collection of photogenerated carriers to be hindered. Therefore, reasonable absorption layer thickness can enhance the spectral response of the device, thereby improving the performance of the entire device. It is very meaningful to study the thickness of the absorption layer. Taking into account the double-layer absorber layer of the lead-tin laminated perovskite solar cell, we kept the thickness of the LBA (TBA) absorber layer unchanged, changed the thickness of the TBA (LBA), and simulated the performance parameters of each device $\left(V_{O C}, J_{S C}, F F, P C E\right)$. The thickness of each absorption layer is between $20 \mathrm{~nm}$ and $500 \mathrm{~nm}$, and we have obtained $\mathrm{V}_{\mathrm{OC}}, \mathrm{J}_{\mathrm{SC}}, \mathrm{FF}$ and PCE diagrams under different absorption layer thicknesses, as shown in Fig 3. In Fig 3(a), we analyzed that the thickness of the LBA has a greater impact on the open circuit voltage $V_{O C}$ than the TBA. As the thickness of TBA increases, $V_{O C}$ shows a downward trend. When the thickness reaches $350 \mathrm{~nm}$, the value of $V_{O C}$ is less than 1. The thickness of TBA is less than $150 \mathrm{~nm}$, and with the increase of LBA thickness, the value of $V_{O C}$ is relatively ideal. When the thickness of TBA is controlled at $50 \mathrm{~nm}$, the thickness of LBA has a small peak in $V_{O C}$ in the range of $20 \mathrm{~nm} \sim 200 \mathrm{~nm}$. Fig. 3(b) shows the $J_{S C}$ curves of different absorption layer thicknesses. In the interval between low LBA thickness and high TBA thickness, or between high LBA thickness and low TBA thickness, $\mathrm{J}_{\mathrm{SC}}$ achieves relatively high values. PCE is an important indicator to measure the performance of the device. From the analysis of the PCE diagram in Fig 3(d), when the 
thickness of the TBA is greater than $150 \mathrm{~nm}$, the PCE of the device decreases rapidly. And when the thickness of TBA is less than 150nm, PCE tends to increase with the thickness of LBA. Considering that the LBA should be reduced as much as possible, we choose the thickness of LBA and TBA to be divided into $20 \mathrm{~nm}$ and $150 \mathrm{~nm}$ as the optimized value.

In order to explain the change of the performance parameters with the doping concentration of the absorber layer. We fixed the $N_{A}$ of $\mathrm{MASnl}_{3}$ to $10^{16} \mathrm{~cm}^{-3}$ and studied the hole quasi-Fermi level $\left(\mathrm{E}_{\mathrm{Fp}}\right)$ distribution, recombination rate $(\mathrm{R})$ and external quantum efficiency QE at different $\mathrm{MAPbl}_{3}$ doping concentrations $\left(10^{15} \mathrm{~cm}^{-3}, 10^{16} \mathrm{~cm}^{-3}, 10^{17} \mathrm{~cm}^{-3}\right)$. Fig 5(a), with the increase of the doping concentration of $\mathrm{MAPbl}_{3}$, the hole quasi-Fermi level $\left(\mathrm{E}_{\mathrm{Fp}}\right)$ shows a downward trend, which is getting lower and lower than the top of the HTL valence band. This facilitates the transition of holes in the perovskite absorption layer to the hole transport layer, and the open circuit voltage $\mathrm{V}_{\text {OC }}$ increases. Fig $5(\mathrm{~b})$, the doping concentration of $\mathrm{MAPbl}_{3}$ is $10^{17} \mathrm{~cm}^{-3}$, the recombination rate $(\mathrm{R})$ increases sharply, and the PCE decreases drastically. Fig.5(c) shows that the external quantum efficiency QE decreases with the increase of $\mathrm{MAPbl}_{3}$ doping concentration, resulting in the obstruction of absorption of photons by the absorption layer, the decrease of photon absorption rate and the decrease of short-circuit current $\mathrm{J}_{\mathrm{SC}}$.

\subsection{Effect of defect density of laminated perovskite absorption layer on device performance}

The morphology and quality of perovskite films are considered to be important parameters that determine the performance of perovskite solar cells (Ball et al. 2013; Azri et al. 2019; Abdelaziz et al. 2020; Singh et al. 2020). Poor quality perovskite films will cause serious defect density (Nt). Electrons and holes will recombine through the trap state, and the carrier recombination dominated by the perovskite absorber layer will seriously affect the performance of the device. Research on the influence of perovskite defect density on battery performance, based on the Shockley-Read-Hall composite model (SRH). The following formula (1) (2) (Zekry et al. 2018):

$$
\begin{aligned}
& R_{S R H}=\frac{\mathrm{np}-n_{i}^{2}}{\tau\left(p+n+2 n_{i} \cosh \left(\frac{E_{i}-E_{t}}{K T}\right)\right)} \\
& \tau=\frac{1}{\sigma \times N_{t} \times v_{\text {th }}}
\end{aligned}
$$

Here, $R_{S R H}$ is the recombination rate, $\mathrm{n}$ and $\mathrm{p}$ are the concentrations of electrons and holes, respectively, and $t$ is the lifetime of carriers. Nt and Et are the defect concentration and defect energy level, respectively, and $\sigma a n d v_{t h}$ represent the carrier trapping cross section and thermal velocity respectively.

$$
L=\sqrt{D \times \tau}
$$


From the formula (1) (2) (3), we get that the carrier lifetime and diffusion length (L), the recombination of electrons and holes are directly related to the defect density. The greater the defect density, the shorter the carrier lifetime and diffusion length, and the aggravation of electron-hole recombination. In order to explore the main factors affecting the performance of the battery, we used the same method to control the defect density of LBA and TBA to simulate the performance parameters of each device to explore the influence on the performance of the device. From the analysis in Fig. 6, we found that as the defect density of LBA and TBA increases, the recombination rate increases, the carrier lifetime decreases, and the overall performance of the device decreases. We found an interesting phenomenon that the highperformance parameter values are close to the LBA side. When the TBA defect density is greater than $10^{18} \mathrm{~cm}^{-3}$, the defect density of the TBA close to the light source has a dominant effect on the overall performance, and the $\mathrm{V}_{\mathrm{OC}}, \mathrm{J}_{\mathrm{SC}}$ and PCE are greatly reduced.

In order to explore the above phenomenon more deeply, we set up another structure, that is, swap the positions of LBA and TBA, as shown in Fig. 8. We call the device on the left side of Fig. 8 structure 1, and the device on the right side as structure 2. The corresponding defect density and the effect on PCE are shown in Tables 3 and 4, and the performance parameters of each device are simulated for structure 2 as shown in Fig. 7. From Fig. 7, we find that when the LBA defect density is greater than $10^{18} \mathrm{~cm}^{-3}$, the defect density of the LBA close to the light source has a dominant effect on the overall performance, and the $V_{O C}, J_{S C}$ and PCE are drastically reduced. In order to verify the above phenomenon, we discussed from the perspective of Shockley-Read-Hall Reorganization Model (SRH). Fig. 8 shows the recombination rate obtained with different defect densities of different structures. The defect density of fixed LBA is $10^{17} \mathrm{~cm}^{-}$ 3 , and the defect density of TBA is $10^{16} \mathrm{~cm}^{-3}, 10^{18} \mathrm{~cm}^{-3}$ and $10^{20} \mathrm{~cm}^{-3}$, respectively. When the TBA defect density is less than $10^{18} \mathrm{~cm}^{-3}$, the recombination rate of structures 1 and 2 is very small, which is consistent with the above analysis. When the defect density of TBA is greater than $10^{18} \mathrm{~cm}^{-3}$, that is, when $10^{20} \mathrm{~cm}^{-3}$ is taken, the recombination rate of structure 1 increases sharply, while that of structure 2 increases a little, which proves that the defect density of the laminated perovskite absorber near the light source side dominates the damage to the overall performance of the device. We need to pay more attention to this phenomenon when manufacturing perovskite solar cells with a laminated structure.

Table 3. The effect of different defect densities of LBA and TBA of structure 1 on PCE 


\begin{tabular}{|c|c|c|c|c|c|c|}
\hline PCE (\%) & \multicolumn{6}{|c|}{$\mathrm{MAPbl}_{3}$ different defect density values $\left(\mathrm{cm}^{-3}\right)$} \\
\hline \multirow[t]{6}{*}{$\mathrm{MASnl}_{3}$ different defect density values $\left(\mathrm{cm}^{-3}\right)$} & & $10^{13}$ & $10^{15}$ & $10^{17}$ & $10^{19}$ & $10^{20}$ \\
\hline & $10^{16}$ & 12.2 & 12.18 & 11.06 & 9.15 & 8.92 \\
\hline & $10^{17}$ & 8.53 & 8.52 & 7.58 & 5.71 & 5.55 \\
\hline & $10^{18}$ & 4.56 & 4.53 & 3.36 & 1.41 & 1.23 \\
\hline & $10^{19}$ & 3.49 & 3.47 & 2.43 & 0.48 & 0.31 \\
\hline & $10^{20}$ & 3.05 & 3.04 & 2.18 & 0.26 & 0.11 \\
\hline
\end{tabular}

Table 4. The effect of different defect densities of LBA and TBA of structure 2 on PCE

\begin{tabular}{|llllllll|}
\hline PCE (\%) & \multicolumn{5}{c|}{ MASnI $_{3}$ different defect density values $\left(\mathrm{cm}^{-3}\right)$} \\
\hline MAPb| $_{3}$ different defect density values $\left(\mathrm{cm}^{-3}\right)$ & $10^{16}$ & $10^{17}$ & $10^{18}$ & $10^{19}$ & $10^{20}$ \\
\cline { 2 - 7 } & & 10.11 & 7.61 & 7.61 & 7.62 & 7.62 \\
\hline $10^{13}$ & $10^{15}$ & 10.09 & 7.58 & 7.59 & 7.59 & 7.6 \\
\hline $10^{17}$ & 8.35 & 4.28 & 5.82 & 5.82 & 5.82 \\
\hline $10^{19}$ & 2.2 & 1.54 & 0.85 & 0.84 & 0.84 \\
\hline $10^{20}$ & 2.22 & 1.55 & 0.29 & 0.34 & 0.34 \\
\hline
\end{tabular}

Table 5 shows the parameter values of each layer after our final optimization, and Fig. 9 shows the J-V and QE curves obtained after optimization. On the basis of reducing the lead content, the parameters of the lead-tin laminated perovskite solar cell are: $\mathrm{V}_{\mathrm{OC}}=1.2578 \mathrm{~V}, \mathrm{~J}_{\mathrm{SC}}=20.5054 \mathrm{~mA} / \mathrm{cm}^{2}, \mathrm{FF}=30.09 \%$ and $\mathrm{PCE}=8.53 \%$.

Table 5 Final parameter optimization values

\begin{tabular}{|llll|}
\hline Optimized Parameters & $\begin{array}{l}\text { Thickness } \\
(\mathrm{nm})\end{array}$ & $\begin{array}{l}\text { Doping Density } \\
\left(\mathrm{cm}^{-3}\right)\end{array}$ & $\begin{array}{l}\text { Defect Density }\left(\mathrm{N}_{\mathrm{t}}\right) \\
\left(\mathrm{cm}^{-3}\right)\end{array}$ \\
\hline $\mathrm{MAPb}_{3}$ & 20 & $1.00 \times 10^{15}$ & $1.00 \times 10^{17}$ \\
\hline $\mathrm{MASnl}_{3}$ & 150 & $1.00 \times 10^{16}$ & $1.00 \times 10^{16}$ \\
\hline
\end{tabular}

\section{Conclusion}


A lead-tin laminated perovskite solar cell was designed and discussed by us, and the absorber layer was made of lead-tin mixed materials. We used the SCAPS-1D simulator to simulate the lead-tin laminated perovskite solar cell. The simulation results show that when the TBA thickness is greater than $150 \mathrm{~nm}$, the PCE of the device decreases rapidly, and when the TBA thickness is less than 150nm, the PCE increases with the increase of the LBA thickness. Considering comprehensively, we choose the thickness of LBA and TBA to be divided into $20 \mathrm{~nm}$ and $150 \mathrm{~nm}$ as the optimized values. The acceptor doping concentration (TBA) and donor doping concentration (LBA) in the laminated structure respectively affect the performance of the device. When the $N_{A}$ of TBA is $10^{16} \mathrm{~cm}^{-3}$ and the $N_{D}$ of LBA is $10^{15} \mathrm{~cm}^{-3}$, which is the top region of the doping concentration, the $V_{O C}$ reaches a high peak and the PCE value is better. We use the hole quasi-Fermi level $\left(\mathrm{E}_{\mathrm{Fp}}\right)$, recombination rate $(\mathrm{R})$ and external quantum efficiency $(\mathrm{QE})$ to reasonably explain the changes of various performance parameters. Defect density is the main culprit for the degradation of device performance. As the defect density of the absorption layer increases, the recombination of carriers in the perovskite light absorption layer will dominate, and each performance parameter has a tendency to decrease. It was finally confirmed that the defect density of LBA and TBA were controlled below $10^{17} \mathrm{~cm}^{-3}$ and $10^{16} \mathrm{~cm}^{-3}$, respectively, and relatively good performance could be obtained. We also found an interesting phenomenon that in the laminated perovskite solar cell, through the recombination rate $(\mathrm{R})$ of different laminated perovskite structures, we proved that the defect density of the laminated perovskite absorber near the light source side dominates the damage to the overall performance of the device. We should pay more attention to this phenomenon when optimizing laminated perovskite solar cells. This work can provide reference for the preparation of high-performance laminated perovskite solar energy in the future.

\section{Declarations}

\section{ACKNOWLEDGMENTS}

This work was partially sponsored by National Natural Science Foundation of China (52076126), and Projects of Shanghai Science and Technology Committee (20DZ1205207).

\section{Declaration of Interest Statement]}

The authors declare that they have no known competing financial interests or personal relationships that could have appeared to influence the work reported in this paper.

\section{References}

[1] Marchioro, A., Teuscher, J., Friedrich, D., Kunst, M., van de Krol, R., Moehl, T., Gratzel, M., Moser, J.E.: Unravelling the mechanism of photoinduced charge transfer processes in lead iodide perovskite solar cells. Nat. Photon. 8, 250-255 (2014).

[2] Stranks, S.D., Eperon, G.E., Grancini, G., Menelaou, C., Alcocer, M.J.P., Leijtens, T., Herz, L.M., Petrozza, A., Snaith, H.J.: Electron-hole diffusion lengths exceeding 1 micrometer in an organometal trihalide 
perovskite absorber. Science. 342, 341-344 (2013).

[3] Xing, G.C., Mathews, N., Sun, S.Y., Lim, S.S., Lam, Y.M., Grätzel, M., Mhaisalkar, S., Sum, T.C.: Longrange balanced electron- and hole-transport lengths in organic-inorganic $\mathrm{CH}_{3} \mathrm{NH}_{3} \mathrm{Pbl}_{3}$. Science. 342, 344347 (2013).

[4] Zhou, H., Chen, Q., Li, G., Luo, S., Song, T.B., Duan, H.S., Hong, Z., You, J., Liu, Y., Yang, Y.: Interface engineering of highly efficient perovskite solar cells. Science. 345, 542-546 (2014).

[5] Jeon, N.J., Noh, J.H., Yang, W.S., Kim, Y.C., Ryu, S., Seo, J., Seok, S.I.: Compositional engineering of perovskite materials for high-performance solar cells. Nature. 517, 476-480 (2015).

[6] Yang, W.S., Noh, J.H., Jeon, N.J., Kim, Y.C., Ryu, S., Seo, J., Seok, S.I.: High-performance photovoltaic perovskite layers fabricated through intramolecular exchange. Science. 348, 1234-1237 (2015).

[7] Arora, N., Dar, M.I., Hindderhofer, A., Pellet, N., Schreiber, F., Zakeeruddin, S.M., Grätzel, M.: Perovskite solar cells with CuSCN hole extraction layers yield stabilized efficiencies greater than $20 \%$. Science. 358, 768-771 (2017).

[8] Tan, Z.-K., Moghaddam, R.S., Lai, M.L., Docampo, P., Higler, R., Deschler, F., Price, M., Sadhanala, A., Pazos, L.M., Credgington, D., Hanusch, F., Bein, T., Snaith, H.J., Friend, R.F.: Bright light-emitting diodes based on organometal halide perovskite. Nat. Nanotechnol. 9, 687-692 (2014).

[9] Wang, N., Cheng, L., Ge, R., Zhang, S., Miao, Y., Zou, W., Yi, C., Sun, Y., Gao, Y., Yang, R., Wei, Y., Guo, Q., Ke, Y., Yu, M., Jin, Y., Liu, Y., Ding, Q., Di, D., Yang, L., Xing, G., Tian, H., Jin, C., Gao, F., Friend, R.H., Wang, J., Huang, W.: Perovskite light-emitting diodes based on solution-processed self-organized multiple quantum wells. Nat. Photon. 10, 699-704 (2016).

[10] Kojima, A., Teshima, K., Shirai, Y., Miyasaka, T.: Organometal Halide Perovskites as Visible Light Sensitizers for Photovoltaic Cells. J. Am. Chem. Soc. 131, 6050-6051 (2009).

[11] Hou, F., Su, Z., Jin, F., Yan, X., Wang, L., Zhao, H., Zhu, J., Chu, B., Li, W.: Efficient and stable planar heterojunction perovskite solar cells with an $\mathrm{MoO}_{3} /$ PEDOT:PSS hole transporting layer. Nanoscale. 7, 9427-9432 (2015).

[12] Ahmadi, M., Wu, T., Hu, B.: A review on organic-Inorganic halide perovskite photodetectors: device engineering and fundamental physics. Adv. Mater. 29, 1605242 (2017).

[13] Dong, Y., Zou, Y., Song, J., Song, X., Zeng, H.: Recent progress of metal halide perovskite photo detectors. J. Mater. Chem. C. 5, 11369-11394 (2017).

[14] Xing, G., Mathews, N., Lim, S.S., Yantara, N., Liu, X., Sabba, D., Grätzel, M., Mhaisalkar, S., Sun, T.C.: Low-temperature solution-processed wavelength-tunable perovskites for lasing, Nat. Mater. 13 (2014) 476-480. 
[15] Yang, W.S., Park, B.-W., Jung, E.H., Jeon, N.J., Kim, Y.C., Lee, D.U., Shin, S.S., Seo, J., Kim, E.K., Noh, J.H., Seok, S.I.: lodide management in formamidinium-lead-halide-based perovskite layers for efficient solar cells. Science. 356, 1376-1379 (2017).

[16] Chen, Z., Wang, J.J., Ren, Y., Yu, C., Shum, K.: Schottky solar cells based on CsSnl 3 thin-films. Applied Physics Letters. 101, 093901 (2012).

[17] Jiang, X., Wang, F., Wei, Q., Li, H., Shang, Y., Zhou, W., Wang, C., Cheng, P., Chen, Q., Chen, L., Ning, Z.: Ultra-high open-circuit voltage of tin perovskite solar cells via an electron transporting layer design. Nature Communications. 11, 1245 (2020).

[18] Meng, X., Wu, T., Liu, X., He, X., Noda, T., Wang, Y., Segawa, H., Han, L.: Highly reproducible and efficient $\mathrm{FASnl}_{3}$ perovskite solar cells fabricated with volatilizable reducing solvent. Journal of Physical Chemistry Letters. 11, 2965-71 (2020).

[19] Liu, X., Wang, Y., Wu, T., He, X., Meng, X., Barbaud, J., Chen, H., Segawa, H., Yang, X., Han, L.: Efficient and stable tin perovskite solar cells enabled by amorphous-polycrystalline structure. Nature Communications. 11, 2678 (2020).

[20] Meng, X., Wang, Y., Lin, J., Liu, X., He, X., Barbaud, J., Wu, T., Noda, T., Yang, X., Han, L.: Surfacecontrolled oriented growth of $\mathrm{FASnl}_{3}$ crystals for efficient lead-free perovskite solar cells. Joule. 4, 902-12 (2020).

[21] Nishimura, K., Kamarudin, M.A., Hirotani, D., Hamada, K., Shen, Q., likubo, S., Minemoto, T., Yoshino, K., Hayase, S.: Lead-free tin-halide perovskite solar cells with 13\% efficiency. Nano Energy. 74, 104858 (2020).

[22] Chen, M., Ju, M.G., Garces, H.F., Carl, A.D., Ono, L.K., Hawash, Z., Zhang, Y., Shen, T., Qi, Y., Grimm, R.L., Pacifici, D., Zeng, X.C., Zhou, Y., Padture, N.P.: Highly stable and efficient all-inorganic lead-free perovskite solar cells with native-oxide passivation. Nature Communications. 10, 16 (2019).

[23] Hu, M., Chen, M., Guo, P., Zhou, H., Deng, J., Yao, Y., Jiang, Y., Gong, J., Dai, Z., Zhou, Y., Qian, F., Chong, X., Feng, J., Schaller, R.D., Zhu, K., Padture, N.P., Zhou, Y.: Sub-1.4eV bandgap inorganic perovskite solar cells with long-term stability. Nature Communications. 11, 151 (2020).

[24] Saliba, M., Matsui, T., Seo, J.Y., Domanski, K., Correa-Baena, J.P., Nazeeruddin, M.K., Zakeeruddin, S.M., Tress, W., Abate, A., Hagfeldt, A., Gratzel, M.: Cesium-containing triple cation perovskite solar cells: improved stability, reproducibility and high efficiency. Energy \& Environmental Science. 9, 1989-97 (2016).

[25] Liu, F., Zhu, J., Wei, J., Li, Y., Lv, M., Yang, S., Zhang, B., Yao, J., Dai, S.: Numerical Simulation: Toward the Design of High-Efficiency Planar Perovskite Solar Cells. Applied Physics Letters. 104, 253508-2535084 (2014). 
[26] Liu, M., Johnston, M.B., Snaith, H.J.: Efficient Planar Heterojunction Perovskite Solar Cells by Vapour Deposition. Nature. 501, 395 (2013).

[27] Hao, F., Stoumpos, C.C., Guo, P., Zhou, N., Marks, T.J., Chang, R.P.H., Kanatzidis, M.G.: SolventMediated Crystallization of $\mathrm{CH}_{3} \mathrm{NH}_{3} \mathrm{Snl}_{3}$ Films for Heterojunction Depleted Perovskite Solar Cells. Journal of the American Chemical Society. 137, 11445-52 (2015).

[28] Devi, C., Mehra, R.: Device simulation of lead-free MASnl 3 solar cell with CuSbS 2 (copper antimony sulfide). J. Mater. Sci. 54, 5615-5624 (2019).

[29] Minemoto, T., Murata, M.: Device Modeling of Perovskite Solar Cells Based on Structural Similarity with Thin Film Inorganic Semiconductor Solar Cells. Journal of Applied Physics. 116, 054505-054505-6 (2014).

[30] Minemoto, T., Murata, M.: Impact of Work Function of Back Contact of Perovskite Solar Cells without Hole Transport Material Analyzed by Device Simulation, Current Applied Physics. 14, 1428-1433 (2014).

[31] Löper, P., Stuckelberger, M., Niesen, B., Werner, J., Filipic, M., Moon, S., Yum, J., Topic, M., De Wolf, S., Ballif, C.: Complex refractive index spectra of $\mathrm{CH}_{3} \mathrm{NH}_{3} \mathrm{Pbl}_{3}$ perovskite thin films determined by spectroscopic ellipsometry and pectrophotometry. J. Phys. Chem. Lett. 6, 66-7 (2015).

[32] Stamate, M.D.: On the dielectric properties of dc magnetron $\mathrm{TiO}_{2}$ thin films, Appl. Surf. Sci. 218, 318323 (2003).

[33] Poplavskyy, D., Nelson, J.: Nondispersive hole transport in amorphous films of methoxy-spirofluorenearylamine organic compound. Appl. Phys. 93, 341-346 (2003).

[34] Liu, D., Kelly, T.L.: Perovskite solar cells with a planar heterojunction structure prepared using roomtemperature solution processing techniques. Nat. Photon. 8, 133 (2013).

[35] Xu, J., Yin, J., Xiao, L., Zhang, B., Yao, J., Dai, S.: Bromide regulated film formation of $\mathrm{CH}_{3} \mathrm{NH}_{3} \mathrm{Pbl}_{3}$ in low-pressure vapor-assisted deposition for efficient planar-heterojunction perovskite solar cells. Solar Energy Materials \& Solar Cells. 157, 1026-1037 (2016).

[36] Noel, N.K., Stranks, S.D., Abate, A., Wehrenfennig, C., Guarnera, S., Haghighirad, A.A., Sadhanala, A., Eperon, G.E., Pathak, S.K., Johnston, M.B., Petrozza, A.M., Herz, L.M., Snaith, H.J.: Lead-free organicinorganic tin halide perovskites for photovoltaic applications. Energy Environ. Sci. 7, 3061-3068 (2014).

[37] Ke, W., Fang, G., Wan, J., Tao, H., Liu, Q., Xiong, L., Qin, P., Wang, J., Lei, H., Yang, G.: Efficient holeblocking layer-free planar halide perovskite thin-film solar cells. Nat. Commun. 6, 1-7 (2015). 
[38] Liu, D., Gangishetty, M.K, Kelly, T.L.: Effect of $\mathrm{CH}_{3} \mathrm{NH}_{3} \mathrm{Pbl}_{3}$ thickness on device efficiency in planar heterojunction perovskite solar cells. Journal of Materials Chemistry A. 2, 19873-19881 (2014).

[39] Xiao, J., Shi, J., Li, D., Meng, Q.: Perovskite thin-film solar cell: excitation in photovoltaic science. ence China Chemistry. 58, 221-238 (2015).

[40] Ball, J.M., Lee, M.M., Hey, A., Snaith, H.: Low-Temperature Processed Meso-Superstructured to ThinFilm Perovskite Solar Cells. Energy \& Environmental Science. 6, 1739-1743 (2013).

[41] Azri, F., Meftah, A., Sengouga, N., Meftah, A.: Electron and hole transport layers optimization by numerical simulation of a perovskite solar cell. Solar Energy. 181, 372-378 (2019).

[42] Abdelaziz, W.S., Zekry, A., Shaker, A., Abouelatta, M.: Numerical study of organic graded bulk heterojunction solar cell using SCAPS simulation. Solar Energy. 211, 375-382 (2020).

[43] Singh, N., Agarwal, A., Agarwal, M.: Numerical simulation of highly efficient lead-free all-perovskite tandem solar cell. Solar Energy. 208, 399-410 (2020).

[44] Zekry, A., Shaker, A., Salem, M.: Chapter 1 - solar cells and arrays: principles, analysis. and design. Advances in Renewable Energies and Power Technologies. 1, 3-56 (2018).

\section{Figures}

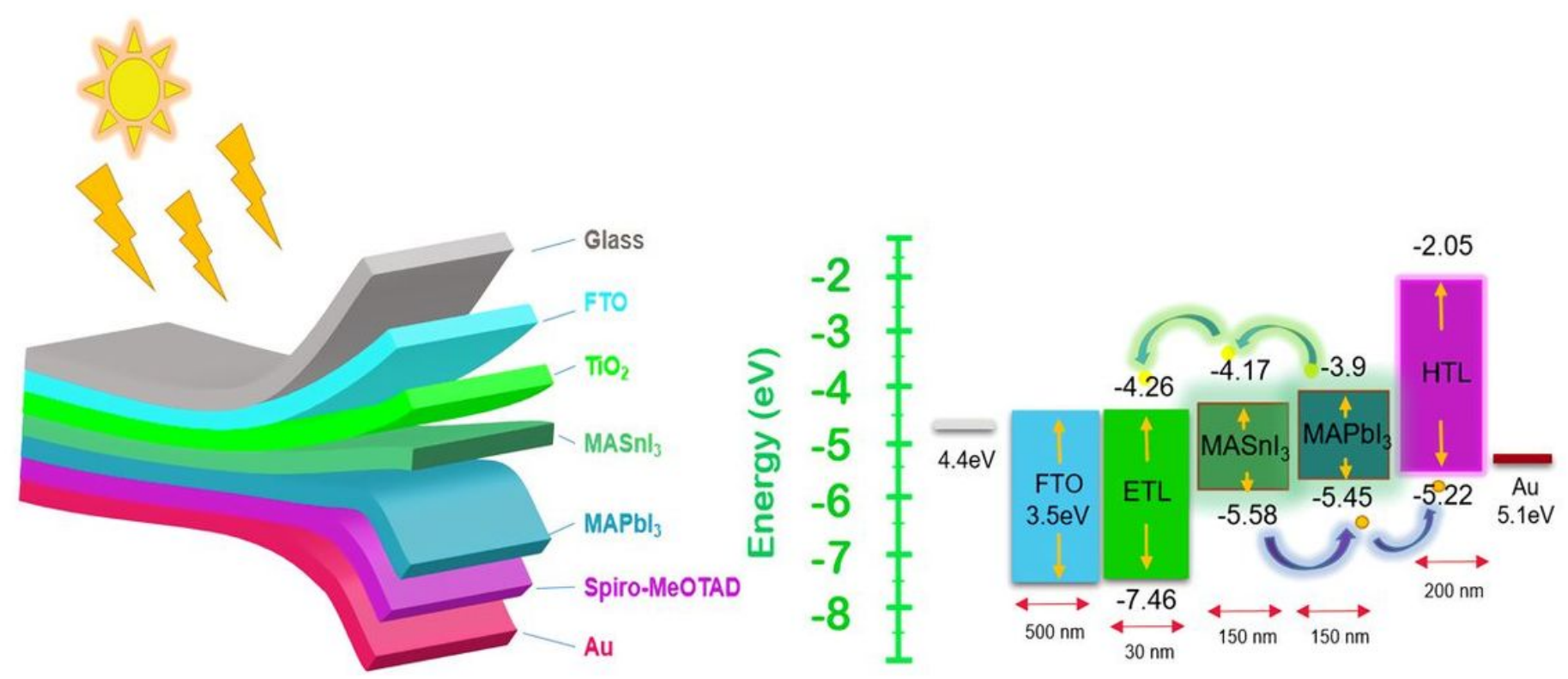

\section{Figure 1}

(a) Device structure; (b) Energy band structure 


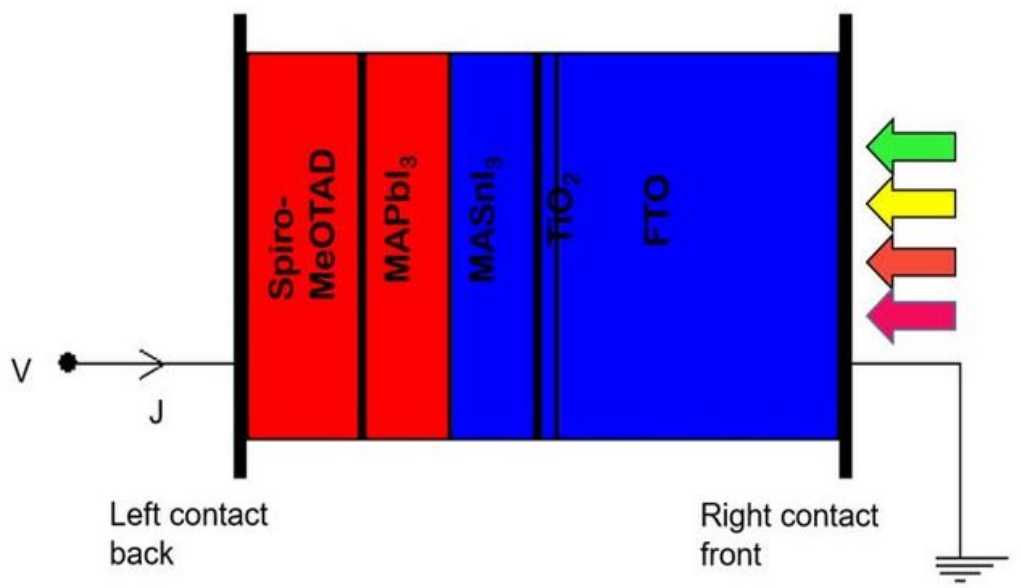

(a)

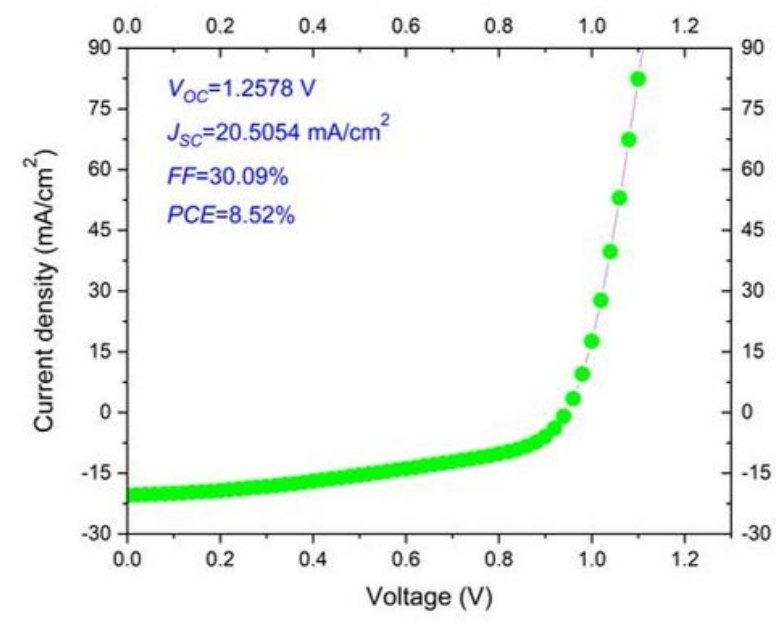

(c)

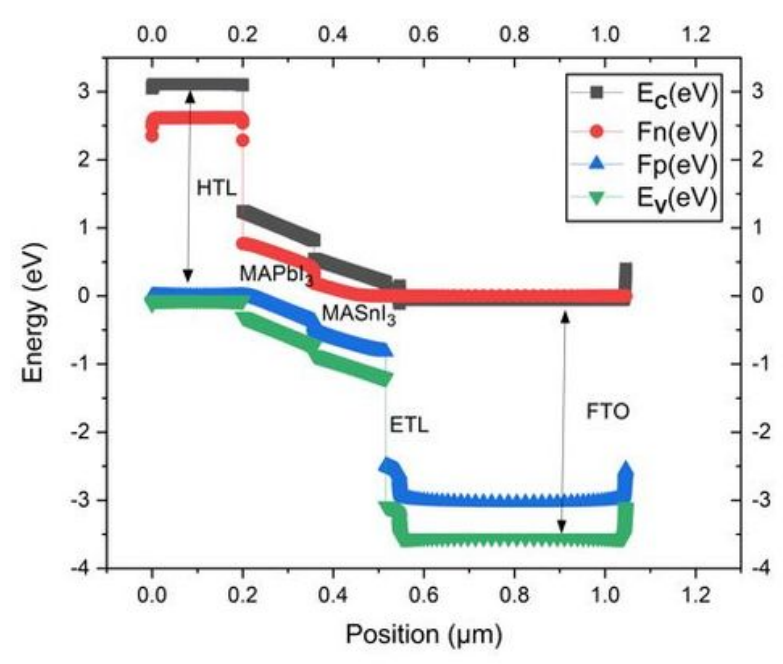

(b)

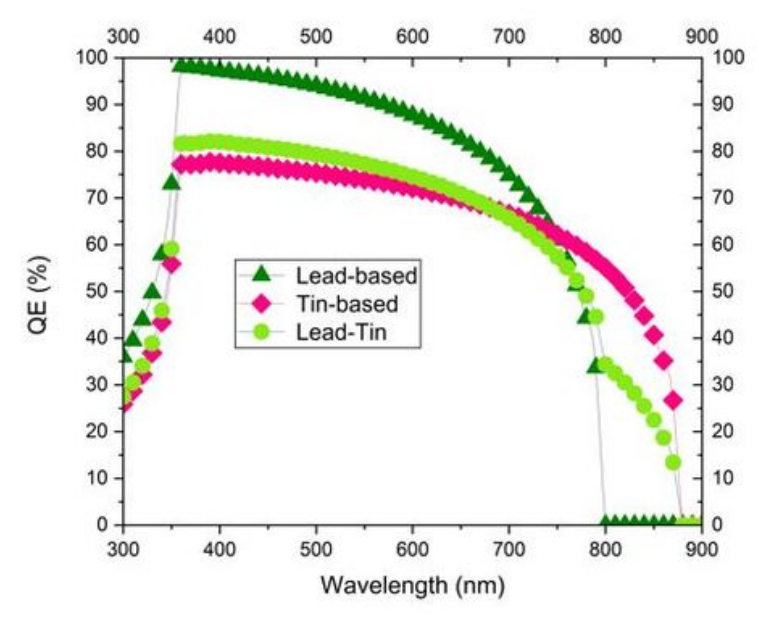

(d)

\section{Figure 2}

Based on the original parameters given in Table 1: (a) Device structure definition panel diagram. (b) Band diagram. (c) J-V curves. (d) QE curves of lead-based, tin-based, and lead-tin laminated structures 


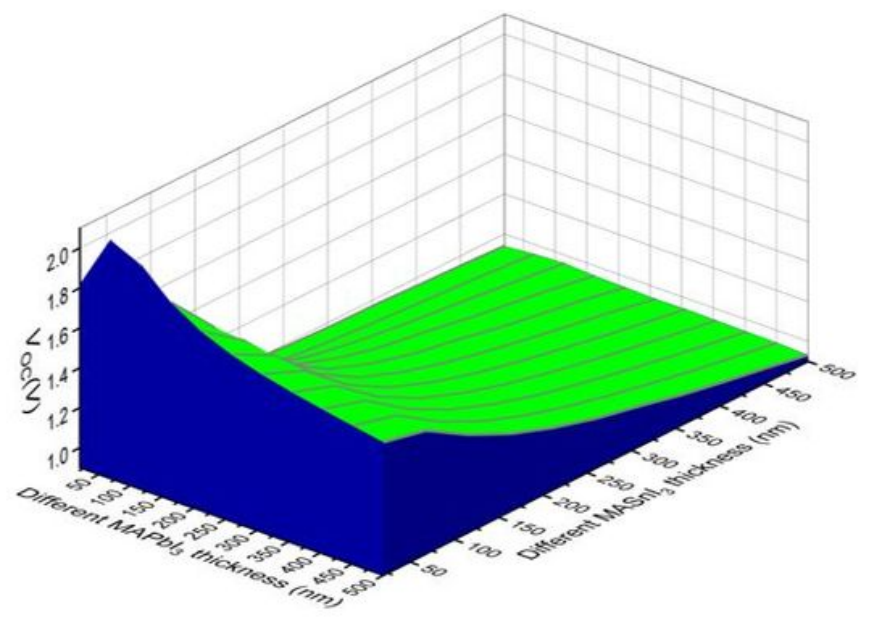

(a)

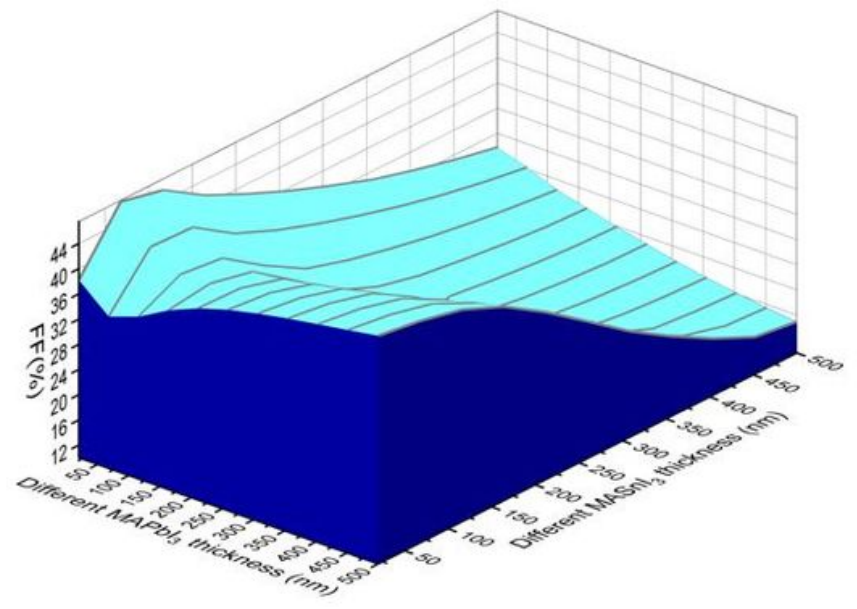

(c)

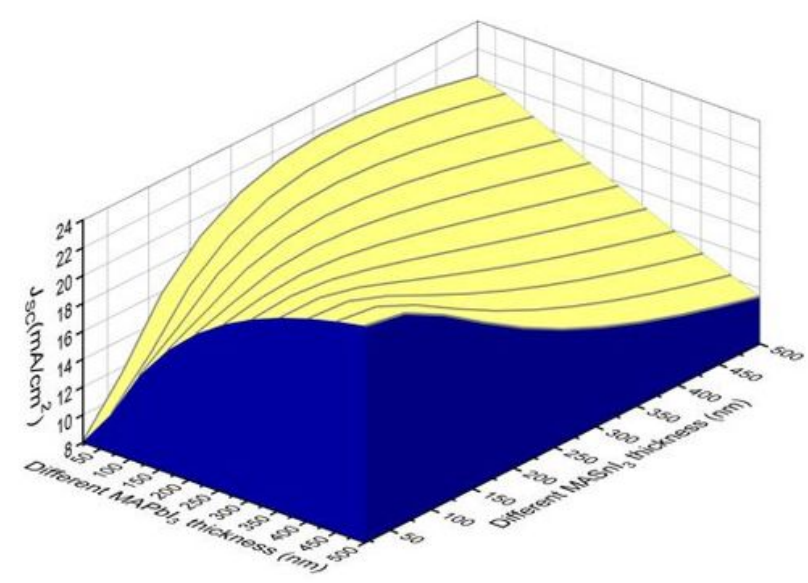

(b)

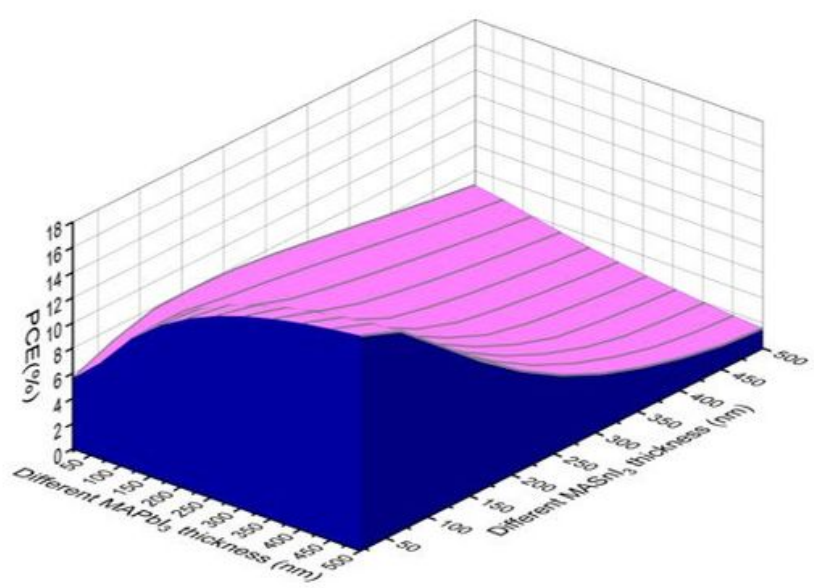

(d)

\section{Figure 3}

The effect of absorber layer thickness on device performance

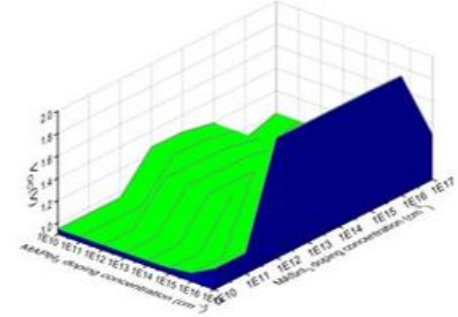

(a)

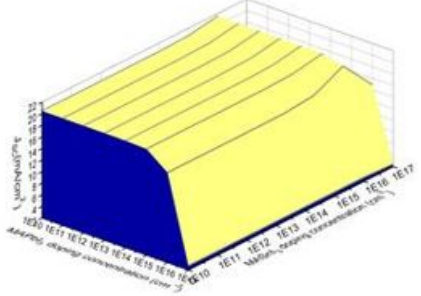

(b)

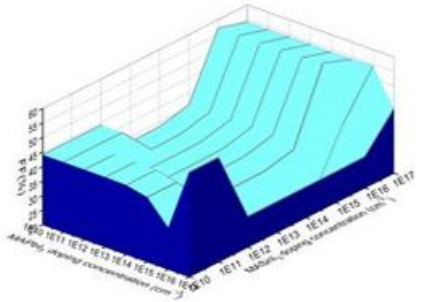

(c)

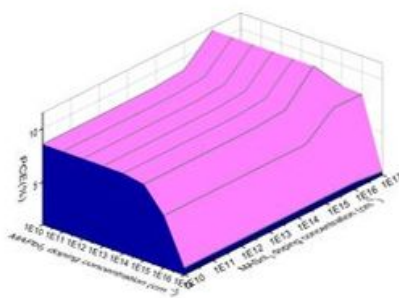

(d)

\section{Figure 4}

The effect of absorber layer doping concentration on device performance 


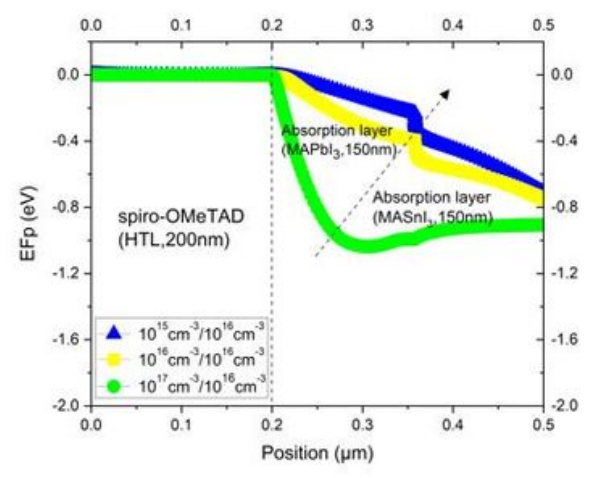

(a)

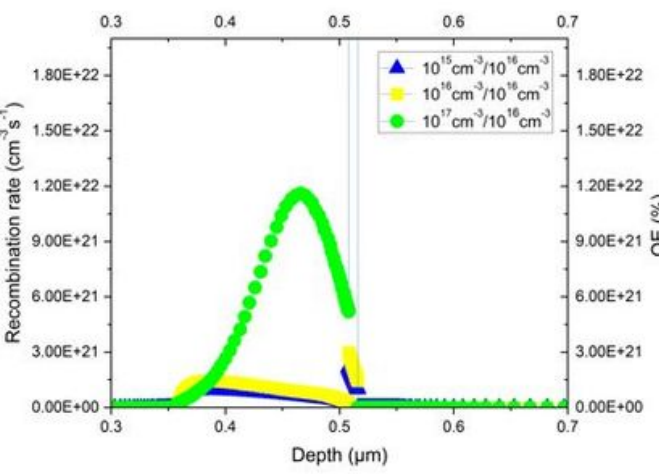

(b)

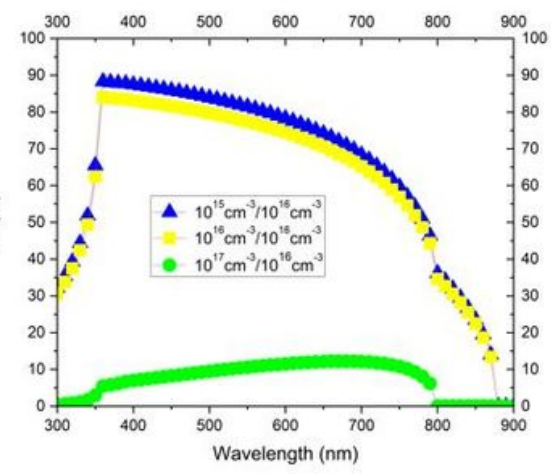

(c)

\section{Figure 5}

Under different doping concentrations of MAPbl3 (the doping concentration of MASnl3 is fixed at $1016 \mathrm{~cm}-3)$ : (a) The distribution of the quasi-Fermi level (EFp) of holes; (b) the change of recombination rate $(\mathrm{R})$; (c) QE curve

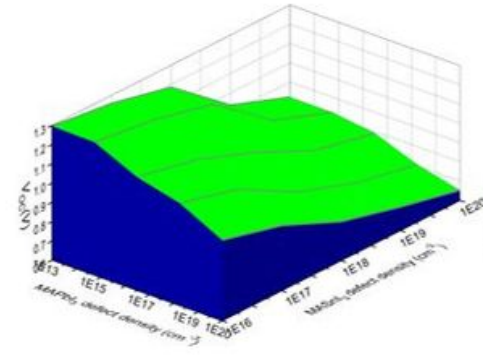

(a)

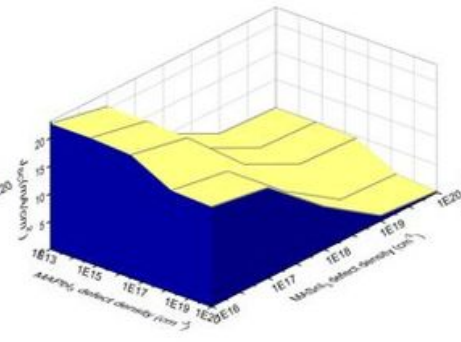

(b)

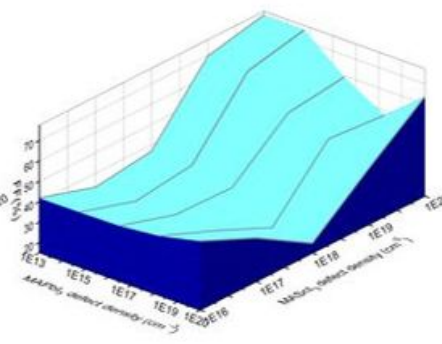

(c)

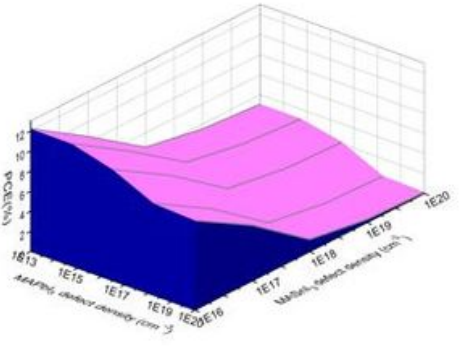

(d)

Figure 6

The effect of absorber layer defect density on device performance (structure 1)
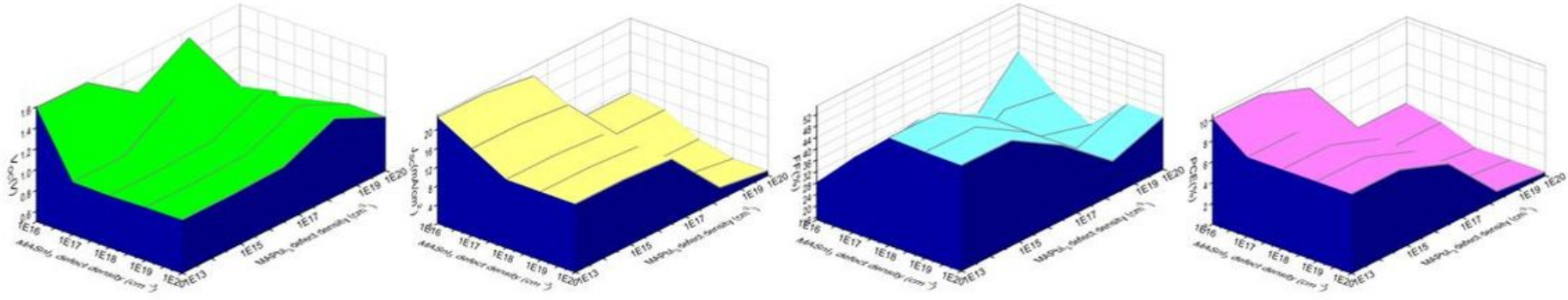

Figure 7

The effect of absorber layer defect density on device performance (structure 2) 


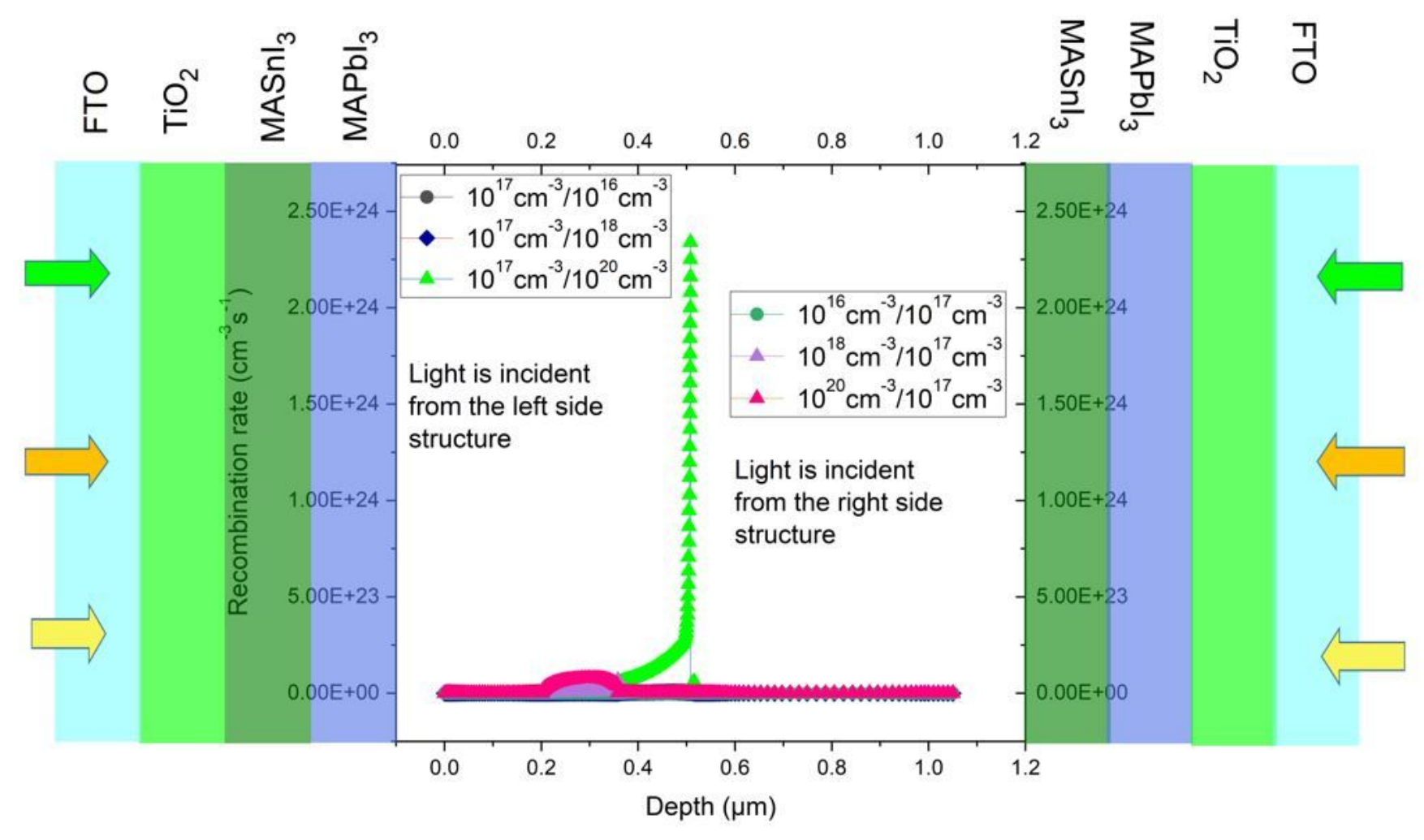

Figure 8

Lead-tin perovskite solar cells with different laminated structures and carrier recombination rate
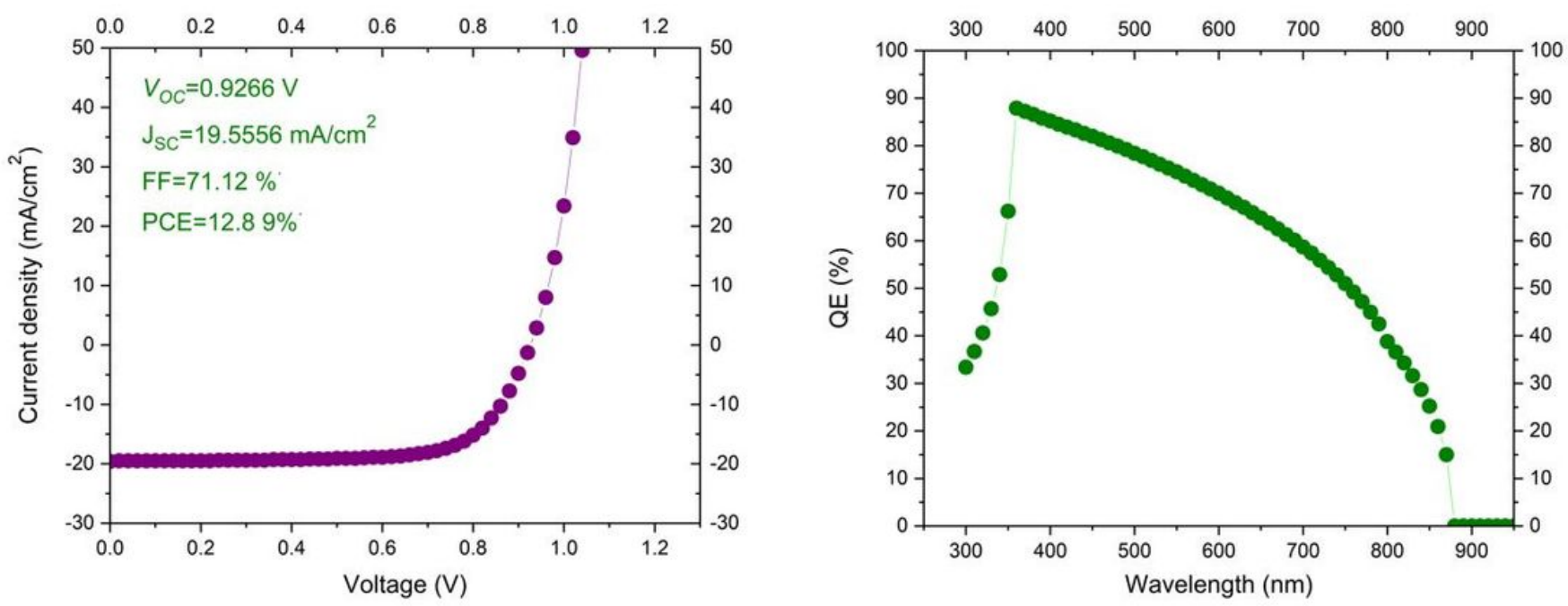

Figure 9

Optimized J-V and QE curve 